\title{
Enxertia em figueira 'Roxo de Valinhos' por borbulhia e garfagem
}

\author{
Tailene Elisa Kotz ( $\left.{ }^{1}\right)$; Rafael Pio $\left({ }^{*}\right)$; Marcelo Angelo Campagnolo $\left({ }^{3}\right)$; Edvan Alves Chagas $\left({ }^{4}\right)$; \\ Idiana Marina Dalastra ( $\left.{ }^{5}\right)$
}

(1) Universidade Estadual do Oeste do Paraná (UNIOESTE), Graduação em Agronomia, Rua Pernambuco, 1777, 785960-000

Marechal Cândido Rondon (PR).

(2) Universidade Federal de Lavras (UFLA), Departamento de Agricultura, Caixa Postal 3037, 37200-000 Lavras (MG).

(3) Universidade Estadual do Oeste do Paraná (UNIOESTE), Programa de Pós-Graduação, 785960-000, Marechal Cândido Rondon (PR).

(4) Empresa Brasileira de Pesquisa Agropecuária (Embrapa, CPAFRR), Caixa Postal 133, 69301-970 Boa Vista (RR).

${ }^{(5)}$ Universidade Estadual Paulista “Júlio de Mesquita Filho" (UNESP), Faculdade de Ciências Agronômicas (FCA), Programa de Pós-

Graduação, 18603-970 Botucatu (SP).

(*) Autor correspondente: rafaelpio@dag.ufla.br

Recebido: 8/abr./2009; Aceito: 14/jul./2010.

\section{Resumo}

Com o intuito de desenvolver um protocolo de enxertia em estacas não enraizadas de figueira 'Roxo de Valinhos' (Ficus carica L.), foram realizados dois experimentos com aplicação de duas técnicas de propagação: borbulhia e garfagem. No primeiro experimento, estacas lenhosas de $20 \mathrm{~cm}$ de comprimento, coletadas da porção mediana dos ramos, de junho a setembro, foram enxertadas por borbulhia tipo placa e "T" normal. No segundo experimento, os propágulos foram coletados em julho e as estacas foram enxertadas pelo método da garfagem, imergindo-se metade das estacas em solução de $2.000 \mathrm{mg} \mathrm{L}^{-1}$ de $\mathrm{AlB}_{\mathrm{B}}$ por 10 segundos e metade permaneceu como controle. Os enxertos foram protegidos com sacos plásticos transparentes (18 $3 \mathrm{~cm}$ ), mantidos por 0, 15, 30, 45 e 60 dias. Posteriormente, as estacas dos dois experimentos foram enterradas a 2/3 de seu comprimento em leito de areia, sob telado (sombrite com 50\% de luminosidade). Aos 60 e 120 dias após a enxertia, mensuraram-se a porcentagem de borbulhas e garfos vivos, a porcentagem de borbulhas e garfos brotados, a porcentagem de borbulhas e garfos vivos em porta-enxertos enraizados e o comprimento médio da brotação do enxerto. Concluiu-se que a enxertia da figueira 'Roxo de Valinhos' pode ser efetuada por borbulhia, pelo método “T”, e por garfagem, devendo-se efetuar a imersão das estacas em AlB e proteger os garfos por 60 dias.

Palavras-chave: Ficus carica L., propagação vegetativa, AlB.

\section{Grafting fig tree 'Roxo de Valinhos' by budding and cleft}

Abstract

Aiming to develop a protocol for grafting unrooted cuttings of 'Roxo de Valinhos' fig tree (Ficus carica L.), two experiments were carried by applying different propagation techniques: budding and grafting. In the first experiment, cuttings of $20 \mathrm{~cm}$ length taken from the middle portion of the branches from June to September were grafted by bud of plate type and normal ' $T$ ' type. In the second experiment, cuttings were collected in July and grafted by the cleft grafting method, by immersing cuttings in $2.000 \mathrm{mg} \mathrm{L}^{-1}$ IBA for $10 \mathrm{~s}$. Control cuttings were not immersed in IBA. The grafts were protected with transparent plastic bags $(18 \times 3 \mathrm{~cm})$, for 0, 15, 30, 45 and 60 days. Cuttings from both experiments were buried 2/3 of their length in sand under greenhouse conditions (50\% of shading). At 60 and 120 days after grafting, percentage of buds and forks alive, buds and forks sprouted, percentage of buds and forks alive on rooted rootstocks, and sprout length were evaluated. As conclusion, grafting of 'Roxo de Valinhos' fig tree can be accomplished by normal "T" type budding and also by grafting, with an immersion of the cuttings in IBA and graft protection for 60 days.

Key words: Ficus carica L., vegetative propagation, IBA. 


\section{INTRODUÇÃO}

Comercialmente, tem-se utilizado apenas o figo 'Roxo de Valinhos' (Ficus carica L.), o que tem proporcionado sérios problemas aos ficicultores paulistas, devido à ocorrência de sérios problemas fitossanitários, com essa cultivar, como os nematóides (Meloidogyne incógnita e Heterodera fici), a ferrugem da figueira (Cerotelium fici) e a seca (Ceratocystis fimbriata Ell. \& Halst.) (ABRAHÃo et al., 2002).

São listadas na literatura centenas de cultivares de figo da espécie F. carica, com diversas características pomológicas e agronômicas (Mars, 2003). Quanto ao desenvolvimento de novas seleçôes de figueiras, os trabalhos de melhoramento são onerosos, diante das características pomológicas das flores se localizarem dentro de um receptáculo fechado (sicônio) de abertura diminuta, o que dificulta a polinização; assim, a diversidade genética da maioria das espécies $F$. carica se baseiam em mutaçôes espontâneas, multiplicadas unicamente por estacas caulinares (Küden e Tanriver, 1998; Nalbant et al., 1998).

Em se tratando da introdução de outras cultivares e espécies do gênero Ficus, vale ressaltar que a quantidade reduzida de propágulos vegetativos advindos de outros países, onera os programas de melhoramento genético, em vista da demanda de longo prazo para se multiplicar as cultivares. Entre os métodos de propagação da figueira, a estaquia é a técnica mais difundida, no entanto, os índices de enraizamento dependem de uma série de fatores, dentre eles, da época de coleta das estacas, da posição do ramo coletado, do tratamento com fitoreguladores e a cultivar ou espécie (Hartmann et al., 2002; Pio et al., 2005; Ohland et al., 2009a).

Previamente à introdução de cultivares ou espécies do gênero Ficus para a diversificação da ficicultura brasileira, é importante verificar a viabilidade e o domínio da técnica de enxertia. Assim, o estudo de técnicas de enxertia de porçóes propagativas da figueira 'Roxo de Valinhos' sobre estacas da mesma cultivar poderá contribuir para a viabilidade e o domínio da técnica de enxertia e auxiliar positivamente na rápida multiplicaçâo de cultivares introduzidas. Assim, pressupóe-se que as técnicas de enxertia podem influenciar diferentemente a porcentagem de brotação e o desenvolvimento dos enxertos e a aplicação do fitorregulador ácido indolbutírico (AIB) poderá viabilizar o enraizamento das estacas enxertadas.

O objetivo do presente trabalho foi definir um protocolo de enxertia da figueira 'Roxo de Valinhos' por borbulhia e garfagem.

\section{MATERIAL E MÉTODOS}

Foram desenvolvidos dois experimentos, entre junho de 2008 e janeiro de 2009. Os propágulos utilizados em ambos os experimentos foram coletados em um pomar comercial de quatro anos de idade de figueira 'Roxo de Valinhos' situado no município de Quatro Pontes (PR).

No primeiro experimento, foram coletadas estacas lenhosas da porçáo mediana dos ramos, na primeira semana de junho a setembro de 2008. As estacas foram padronizadas com $20 \mathrm{~cm}$ de comprimento, aproximadamente 15 $\mathrm{mm}$ de diâmetro e quatro nós, sendo efetuado um corte em bisel na base da estaca e outro reto no ápice. Simultaneamente a cada época, foram coletadas estacas da porção apical dos ramos das mesmas figueiras, para se extrair as borbulhas para enxertia. Após a coleta, as estacas foram mantidas úmidas para facilitar a operação de enxertia. Para isso, as estacas foram mantidas entre camadas de jornal umedecido em geladeira (à temperatura de $4{ }^{\circ} \mathrm{C}$ ).

Foram realizadas enxertias pelo método de borbulhia tipo placa (cortes quadrados de $10 \mathrm{~mm}^{2}$ entre dois nós da estaca, inserindo-se nesse local uma borbulha de mesma dimensão) e "T" normal (corte superficial na casca da estaca, de $20 \mathrm{~mm}$ na vertical e $10 \mathrm{~mm}$ na horizontal), sem auxílio de máquinas de enxertia. As borbulhas foram extraídas das gemas verdes e inchadas da porção apical do ramo. Após a inserção da gema, as borbulhas foram amarradas com fita plástica transparente, tomando-se o cuidado da gema permanecer exposta. Todas as estacas enxertadas foram tratadas em solução de $2.000 \mathrm{mg} \mathrm{L}^{-1}$ de AIB por $10 \mathrm{~s}$ (Ohland et al., 2009b). No preparo da solução hidroalcóolica do AIB, pesou-se $0,2 \mathrm{~g}$ de AIB em balança semianalítica, dissolvendo-se em $50 \mathrm{~mL}$ de álcool em becker, com auxílio de agitador eletromagnético. Após totalmente dissolvido o AIB, completou-se o volume para $100 \mathrm{~mL}$ com água destilada, obtendo-se então a concentração de $2.000 \mathrm{mg} \mathrm{L}^{-1}$ de AIB.

No segundo experimento, os propágulos foram coletados no fim do mês de julho, sendo as estacas preparadas igualmente ao primeiro experimento. Foi realizado o corte "T" normal entre dois nós da estaca, inserindo-se na incisão garfos contendo três gemas e aproximadamente cinco centímetros de comprimento (corte em bisel na base e reto no ápice), oriundos da porção apical dos ramos, amarrados com fita plástica transparente, sem auxílio de máquinas de enxertia. Em seguida, metade das estacas enxertadas tiveram suas bases tratadas em solução de $2.000 \mathrm{mg} \mathrm{L}^{-1}$ de AIB por 10 segundos e metade permaneceu ausente de tratamento. Com o intuito de evitar a desidratação dos garfos, os enxertos foram protegidos com sacos plásticos transparentes $(18 \times 3 \mathrm{~cm})$, sendo esses sacos plásticos mantidos por diferentes tempos na região de enxertia até o ápice do garfo: 15, 30, 45 e 60 dias, além do controle sem proteção.

Posteriormente, as estacas foram enterradas a $2 / 3$ de seu comprimento em leito de areia de grânulos finos (dimensóes de 0,9 m x 5,0 m), sob telado constituído de sombrite com $50 \%$ de luminosidade. Durante a fase experimental, o leito de enraizamento foi diariamente umedecido com $2 \mathrm{~L}$ de água. 
O delineamento utilizado foi o inteiramente casualizado. No primeiro experimento adotou-se o esquema fatorial 4 × 2, (4 épocas de realização e 2 métodos de enxertia). No segundo experimento, o esquema fatorial utilizado foi o 5 x 2 (5 tempos de permanência da proteção do enxerto e 2 tratamentos). Em ambos os experimentos, utilizaram-se quatro repetiçóes e 10 enxertos por unidade experimental.

Aos 60 dias após a enxertia, foi mensurada a porcentagem de borbulhas e garfos vivos, brotados, vivos em portaenxertos enraizados e o comprimento médio da brotação $(\mathrm{cm})$, conservando-se uma única brotação por garfo e repetindo-se as mensuraçóes nos dois experimentos aos 120 dias. Os dados foram submetidos à análise de variância, as médias comparadas pelo teste Tukey, ao nível de 5\% de probabilidade. As análises foram realizadas pelo programa computacional Sistema para Análise de Variância - SISVAR.

\section{RESULTADOS E DISCUSSÃO}

No experimento de enxertia por borbulhia, houve maior porcentagem de borbulhas vivas nas enxertias realizadas entre junho e agosto, independentemente do método de enxertia utilizado e em ambas as avaliaçóes, ocorrendo $73 \%$ de sobrevivência ao final da última avaliação (Tabela 1). A maior porcentagem de borbulhas vivas em porta-enxertos enraizados ocorreu na primeira avaliação de agosto, em ambos os métodos de enxertia, período que coincide com o início da brotaçáo dos ramos das plantas no campo, ou seja, ao término do período de dormência; em setembro, o método " $T$ " normal proporcionou resultado semelhante a agosto (Tabela 1). No entanto, na última avaliação, não houve diferença entre os métodos de enxertia, porém, em enxertias realizadas nos três primeiros meses os resultados foram semelhantes, com mais de 96\% de borbulhas vivas em porta-enxertos enraizados.
Esses resultados demonstram a necessidade do portaenxerto enraizar para a borbulha sobreviver, como pode ser notado nas enxertias realizadas em setembro, na avaliação aos 120 dias, enfatizando que a causa da baixa sobrevivência das borbulhas ocorreu em detrimento do baixo enraizamento das estacas. A causa do insucesso da enxertia nesse mês pode estar relacionada ao fato de as plantas terem saído da dormência hibernal e permanecerem em estado de vegetação e início de produção. A utilização de estacas provenientes de plantas em produçáo diminui o percentual de enraizamento, em função da baixa disponibilidade de hidratos de carbono (DeL-Rio e Caballero, 1991).

Segundo a literatura, as estacas medianas de figueira 'Roxo de Valinhos' possuem alta porcentagem de enraizamento, quando coletadas em plantas entre o período de entrada da dormência até a época de realização da poda (julho), nas condiçôes do Sul de Minas Gerais (NorberTO et al., 2001); no entanto, coletas tardias depararam com acentuada queda do potencial rizogênico das estacas, mesmo com a aplicação exógena de auxinas, conforme relata OHLAND et al. (2009b), em trabalho realizado no Oeste paranaense.

No caso de estacas lenhosas, reservas mais abundantes de carboidratos correlacionam-se com maiores porcentagens de enraizamento e sobrevivência de estacas. Assim, a real importância dos carboidratos para formação de raízes é que a auxina requer fonte de carbono para a biossíntese de ácidos nucléicos e proteínas, levando à necessidade de energia e carbono para formação das raízes (HARTMANN et al., 2002).

A enxertia pelo método "T" normal realizada em agosto favoreceu a maior porcentagem de borbulhas brotadas na primeira avaliação $(42,5 \%)$. No entanto, houve decréscimo em $15 \%$ desse índice na avaliação realizada aos 120 dias $(27,5 \%)$, o que ocasionou similaridade aos resultados avaliados com a enxertia pelo mesmo método, realizada em junho ( $25 \%$ de borbulhas brotadas) e

Tabela 1. Porcentagem de borbulhas vivas, porcentagem de borbulhas vivas em porta-enxertos enraizados, porcentagem de borbulhas brotadas e comprimento médio da brotaçáo de borbulhas de figueira 'Roxo de Valinhos' (Ficus carica L.), enxertadas em estacas lisas medianas por enxertia através de duas metodologias, em diferentes épocas

Época da
enxertia


ainda com a enxertia tipo placa (Tabela 1). Quanto ao comprimento médio da brotação, constatou-se na primeira avaliação que as enxertias realizadas em setembro por " $T$ " normal e em agosto independente do método, ocasionaram brotaçôes de maiores comprimentos; porém, na última avaliação, a enxertia pelo método " $T$ " normal realizada em agosto ocasionou o maior crescimento das brotaçôes (Tabela 1).

Essa diferença expressiva no comprimento da brotação da enxertia pelo método "T" normal realizada em agosto, em comparação aos resultados das enxertias realizadas nos outros meses, pode estar relacionada ao potencial rizogênico das estacas coletadas nesse mês, principalmente quanto ao aumento do número de raízes, o que ocasionou aumento na taxa respiratória da estaca e desencadeou a mobilização das reservas (carboidratos), favorecendo a emissão da brotaçáo do enxerto.

O fato da enxertia tipo placa náo ter promovido resultados similares ao " $\mathrm{T}$ " normal, pode estar relacionado à incisão realizada logo acima do nó da estaca, onde se localizava uma gema; esse corte promoveu o forçamento da brotação da gema da estaca, desfavorecendo a translocação de água e reservas (carboidratos) para a borbulha enxertada, obtendo valores menores em comparação ao método "T" normal; devido ao tipo do corte (incisão vertical e acima incisão horizontal) foi favorecida a translocaçáo de água e reservas à gema enxertada e náo à gema da estaca. Segundo MaIa de Souza (2003), incisóes horizontais acima de gemas caulinares em plantas de figueiras estimulam a saída da dormência das gemas e favorecem a emissão das brotações.

Neste experimento, a porcentagem de brotação não foi elevada na enxertia por borbulhia em estacas de figueira não enraizadas, o que pode ter sido causado pela pouca reserva armazenada no fragmento enxertado, desfavorecendo a cicatrizaçáo da região enxertada.

$\mathrm{Na}$ enxertia por garfagem, obteve-se $100 \%$ de garfos brotados nas duas avaliaçóes, quando se preservou a proteção no enxerto por 60 dias para as estacas que receberam o tratamento com a auxina sintética (Tabela 2). Verificando-se a sobrevivência dos garfos na ausência e na proteção do enxerto por 15 dias, nota-se acentuada queda da sobrevivência dos garfos em relaçáo à primeira e à última avaliação.

Com relação à sobrevivência dos garfos, em relação ao tratamento ou não com AIB na base das estacas, para enxertos protegidos por 30 dias, houve diferença de $68,7 \%$ de sobrevivência dos garfos; para enxertos protegidos por 45 dias, a diferença foi de $11,6 \%$ e para enxertos protegidos por 60 dias não houve diferença, ocorrendo $100 \%$ de sobrevivência dos garfos independentemente do tratamento com AIB (Tabela 2). Por esses dados, nota-se que quanto menor o tempo de proteçáo dos garfos, maior a possibilidade de ocorrer o enraizamento das estacas para os garfos permanecerem vivos.

Essa afirmação pode ser reforçada se analisados os dados da porcentagem de garfos vivos em porta-enxertos enraizados (Tabela 2), onde ocorreram melhores resultados em enxertos protegidos por 45 dias ou mais, nas duas avaliaçóes, independentemente do tratamento com AIB na estaca. Em enxertos protegidos por 30 dias obteve-se $91,7 \%$ de sobrevivência dos garfos com o uso de $2.000 \mathrm{mg} \mathrm{L}^{-1}$ de AIB.

A importância da aplicação exógena de $2.000 \mathrm{mg} \mathrm{L}^{-1}$ de AIB na melhoria da rizogênese em estacas lenhosas de figueira foi mencionada em outros trabalhos (KARADENIZ, 2003; Pio et al., 2006; OHLAnd et al., 2009a). No caso da enxertia por garfagem, há necessidade de se proteger os

Tabela 2. Porcentagem de garfos vivos, porcentagem de garfos vivos em porta-enxertos enraizados, porcentagem de garfos brotados e comprimento médio da brotação, de garfos de figueira 'Roxo de Valinhos' (Ficus carica L.), enxertados em estacas lisas medianas, tratadas ou não com AIB (2.000 $\left.\mathrm{mg} \mathrm{L}^{-1}\right)$ por enxertia por garfagem em função do tempo de proteção do garfo

\begin{tabular}{|c|c|c|c|c|c|c|c|c|}
\hline \multirow{3}{*}{$\begin{array}{l}\text { Tempo da } \\
\text { proteção }\end{array}$} & \multicolumn{4}{|c|}{ \% Garfos vivos* } & \multicolumn{4}{|c|}{$\%$ Garfos vivos em porta-enxertos enraizados } \\
\hline & \multicolumn{2}{|c|}{60 dias } & \multicolumn{2}{|c|}{120 dias } & \multicolumn{2}{|c|}{60 dias } & \multicolumn{2}{|c|}{120 dias } \\
\hline & Sem AlB & $\begin{array}{c}2.000 \mathrm{mg} \mathrm{L}^{-1} \\
\text { AIB }\end{array}$ & Sem AIB & $\begin{array}{c}2.000 \mathrm{mg} \mathrm{L}^{-1} \\
\text { AIB }\end{array}$ & Sem AIB & $\begin{array}{c}2.000 \mathrm{mg} \mathrm{L}^{-1} \\
\text { AIB }\end{array}$ & Sem AIB & $\begin{array}{c}2.000 \mathrm{mg} \mathrm{L}^{-1} \\
\text { AIB }\end{array}$ \\
\hline 0 & $20,8 \mathrm{AC}$ & $\mathrm{OAC}$ & O Ad & $\mathrm{OAC}$ & $50,0 \mathrm{Ac}$ & $50,0 \mathrm{Ac}$ & $0 \mathrm{Ac}$ & $0 \mathrm{Ad}$ \\
\hline 15 & $16,7 \mathrm{Bc}$ & $65,0 \mathrm{Ab}$ & $\mathrm{OBd}$ & $41,7 \mathrm{Ab}$ & $50,0 \mathrm{Bc}$ & $75,0 \mathrm{Ab}$ & $\mathrm{OBC}$ & $50,0 \mathrm{Ac}$ \\
\hline 30 & $25,0 \mathrm{Bc}$ & 93,7 Aa & $25,0 \mathrm{Bc}$ & 93,7 Aa & $75,0 \mathrm{Bb}$ & $91,7 \mathrm{Aa}$ & $50,0 \mathrm{Bb}$ & $79,2 \mathrm{Ab}$ \\
\hline 45 & $81,7 \mathrm{Bb}$ & $93,3 \mathrm{Aa}$ & $81,7 \mathrm{Bb}$ & $93,3 \mathrm{Aa}$ & 91,7 Aa & $90,0 \mathrm{Aa}$ & $100,0 \mathrm{Aa}$ & $95,0 \mathrm{Aa}$ \\
\hline 60 & 100,0 Aa & $100,0 \mathrm{Aa}$ & $100,0 \mathrm{Aa}$ & $100,0 \mathrm{Aa}$ & $87,5 \mathrm{Aa}$ & 91,7 Aa & $100,0 \mathrm{Aa}$ & $100,0 \mathrm{Aa}$ \\
\hline \multirow[t]{2}{*}{ C.V.(\%) } & \multicolumn{2}{|c|}{22,10} & \multicolumn{2}{|c|}{23,15} & \multicolumn{2}{|c|}{22,11} & \multicolumn{2}{|c|}{11,01} \\
\hline & \multicolumn{4}{|c|}{$\%$ Garfos brotados } & \multicolumn{4}{|c|}{ Comprimento médio da brotação $(\mathrm{mm})$} \\
\hline 0 & $\mathrm{OAc}$ & $\mathrm{OAc}$ & $\mathrm{OAC}$ & $0 \mathrm{Ac}$ & O Ac & $0 A b$ & $0 A b$ & $0 \mathrm{Ab}$ \\
\hline 15 & $\mathrm{OAc}$ & $5,0 \mathrm{Ac}$ & $\mathrm{OAc}$ & $15,0 \mathrm{Ac}$ & $\mathrm{OAc}$ & $3,0 \mathrm{Ab}$ & $0 \mathrm{Ab}$ & $7,8 \mathrm{Ab}$ \\
\hline 30 & $10,0 \mathrm{Bc}$ & $55,0 \mathrm{Ab}$ & $10,0 \mathrm{Bc}$ & $60,0 \mathrm{Ab}$ & $5,6 \mathrm{Bb}$ & $14,8 \mathrm{Aa}$ & $7,0 \mathrm{Bb}$ & $37,7 \mathrm{Aa}$ \\
\hline 45 & $50,0 \mathrm{Bb}$ & $65,0 \mathrm{Ab}$ & $50,0 \mathrm{Bb}$ & $70,0 \mathrm{Ab}$ & 18,4 Aa & $22,2 \mathrm{Aa}$ & $34,0 \mathrm{Aa}$ & $43,0 \mathrm{Aa}$ \\
\hline 60 & 70,0 Ba & $100,0 \mathrm{Aa}$ & 70,0 Ba & $100,0 \mathrm{Aa}$ & 19,2 Aa & 19,3 Aa & $38,3 \mathrm{Aa}$ & 43,1 Aa \\
\hline C.V.(\%) & \multicolumn{2}{|c|}{25,18} & \multicolumn{2}{|c|}{26,73} & \multicolumn{2}{|c|}{22,11} & \multicolumn{2}{|c|}{21,11} \\
\hline
\end{tabular}

* Médias seguidas pela mesma letra em maiúsculo na linha e mesma letra em minúsculo na coluna, năo diferem entre si pelo teste Tukey a $5 \%$ de probabilidade. 
garfos até que ocorram simultaneamente, a cicatrização do enxerto e o início da rizogênese da estaca, sendo esse efeito fisiológico auxiliado pelo tratamento com AIB.

Essa ação sinérgica entre a proteção dos garfos e a aplicação exógena de AIB na melhoria da rizogênese da estaca favoreceu a porcentagem de garfos brotados, onde se obteve $100 \%$ de brotação em estacas que receberam o tratamento com AIB e, simultaneamente, tiveram seus garfos protegidos por 60 dias, ocorrendo $30 \%$ a mais de brotação em relação ao mesmo tratamento, porém sem a aplicação da auxina sintética (Tabela 2).

Com relação ao comprimento da brotação, houve melhores resultados quando se preservou a proteção no enxerto por 30 dias ou mais em estacas tratadas com AIB e com enxertos protegidos por mais de 45 dias, para as estacas que não receberam o tratamento com a auxina sintética, nas duas avaliaçôes realizadas (Tabela 2).

Em uma síntese entre os tipos de enxertia estudados em estacas náo enraizadas para a figueira, os resultados superiores observados com a enxertia por garfagem em relação à enxertia por borbulhia, estão relacionados à quantidade de reservas presentes endogenamente no fragmento enxertado. Como a borbulha praticamente náo continha reserva, em detrimento de seu tamanho, a cicatrizaçáo inicial do enxerto e o desenvolvimento da brotação ficou totalmente dependente da estaca, que por não ter sistema radicular inicial, desfavoreceu o sucesso desse tipo de enxertia. O contrário ocorreu com a enxertia por garfagem, em que cicatrização da enxertia e a brotação das gemas ocorreram independentes da estaca, e após ter ocorrido a rizogênese, veio a favorecer o desenvolvimento do enxerto.

\section{CONCLUSÃO}

A enxertia da figueira 'Roxo de Valinhos' pode ser efetuada por borbulhia e garfagem. Para o tipo borbulhia, devem-se realizar enxertias em agosto pelo método "T" normal, período em que coincide com o início da brotação dos ramos das plantas em campo, ou seja, ao término do período de dormência. Para a enxertia por garfagem, devem-se tratar as estacas com AIB e proteger os garfos por 60 dias.

\section{AGRADECIMENTOS}

Ao Conselho Nacional de Desenvolvimento Científico e Tecnológico - CNPq, pelo auxílio financeiro ao desenvolvimento do projeto.

\section{REFERÊNCIAS}

ABRAHÃO, E.; ALVARENGA, A.A.; FRÁGUAS, J.C.; SILVA, V.J. A cultura da figueira (Ficus carica L.) na regiấo de Lavras, MG: situação atual e perspectivas. Ciência e Agrotecnologia, v.26, p.643646, 2002.

DEL-RIO, C.; CABALLERO, J.M. Effects of carbohydrate content on the seasonal rooting of vegetative and reproductive cuttings of olive. Journal of Horticultural Science, v.66, p.301-309, 1991.

HARTMANN, H.T.; KESTER, D.E.; DAVIES JUNIOR, F.T.; GENEVE, R.L. Plant propagation: principles and practices. 7.ed. New Jersey: Prentice Hall, 2002. 880p.

KARADENIZ, T. A study on some fruit characteristics and propagations of these by hardwood cuttings of local fig cultivars grown in ordu (Turkey). Acta Horticulturae, n.605, p.107-112, 2003.

KÜDEN, A.B.; TANRIVER, E. Plant genetic resources and selection studies on figs in the east mediterranean and south east anatolia regions. Acta Horticulturae, n.480, p.49-54, 1998.

MAIA de SOUZA, R.M. Fig culture techniques. Acta Horticulturae, n.605, p.99-101, 2003.

MARS, M. Fig (Ficus carica L.) genetic resources and breeding. Acta Horticulturae, n.605, p.19-27, 2003.

NALBANT, M.; SAHIN, N.; AYDIN, S. Fig genetic resources at the fig research institute (Aydin/Turkey). Acta Horticulturae, n.480, p.43-48, 1998.

NORBERTO, P.M.; CHALFUN, N.N.J.; PASQUAL, M.; VEIGA, R.D.; PEREIRA, G.E.; MOTA, J.H. Efeito da época de estaquia e do AIB no enraizamento de estacas de figueira (Ficus carica L.). Ciência e Agrotecnologia, v.25, p.533-541, 2001.

OHLAND, T.; PIO, R.; CHAGAS, E.A.; BARBOSA, W. DALASTRA, I.M.; KOTZ, T.E. Enraizamento de estacas apicais lenhosas de figueira 'Roxo de Valinhos' com aplicação de AIB e cianamida hidrogenada. Revista Brasileira de Fruticultura, v.31, p.273-279, 2009a.

OHLAND, T.; PIO, R.; CHAGAS, E.A.; BARBOSA, W.; KOTZ, T.E.; DANELUZ, S. Enraizamento de estacas apicais de figueira 'Roxo de Valinhos' em função de época de coleta e AIB. Ciência e Agrotecnologia, v.33, p.74-78, 2009b.

PIO, R.; ARAÚJO, J.P.C.; BASTOS, D.C.; SIQUEIRA, A.A.; ENTELMANN, F.A.; SCARPARE FILHO, J.A.; MOURÃO FILHO, F.A.A. Substratos no enraizamento de estacas herbáceas de figueira oriundas da desbrota. Ciência e Agrotecnologia, v.29, p.604-609, 2005.

PIO, R.; RAMOS, J.D.; CHALFUN, N.N.J.; GONTIJO, T.C.A.; MENDONÇA, V.; CARRIJO, E.P.; CHAGAS, E.A. Propagação de estacas apicais de figueira: diferentes ambientes, ácido indolbutírico e tipo de estaca. Ciência e Agrotecnologia, v.30, p.1021-1026, 2006. 